\title{
Hydraulic borehole mining method possible application at Middle Larba alluvial gold field
}

\author{
Vikror Rochev ${ }^{1 *}$ \\ ${ }^{1}$ North-Eastern Federal University. M.K. Ammosov, Technical Institute (division) Neryungri, Sakha \\ Republic (Yakutia), Russia.
}

\begin{abstract}
Gold on placer deposits is mainly extracted in two ways: open and underground. But the open method of mining has a great negative impact on the environment, and the mine method is characterized by high labor intensity, capital and operating costs. As an alternative to these methods of development of alluvial gold, the hydraulic borehole mining method can be used. The use of a well as a hydro-mining creates favorable opportunities for ensuring nature protection and safe operation. When applying the method, the well does not have hydraulic extractions: stripping, this allows preserving the cultural layer of the soil in its integrity; explosive, loading works and use of motor transport, excluding dustiness and gas pollution of the atmosphere; the hard and harmful work for people's health is eliminated. The method of well drilling requires further serious scientific, technical and developmental studies to increase its reliability and expand the field of application. Alluvial deposits of gold are the most favorable objects for hydraulic borehole mining under their mining and geological conditions. Recently, new gold placers have been identified and are being surveyed at a depth of more than $40 \mathrm{~m}$. With a high content of metal in them, these placers are very promising for mining by the hydraulic borehole mining method. The reserves of gold in these fields reach several tens of tons. Against the backdrop of a reduction in inventories for open and underwater mining, large technical difficulties, significant capital investments and operating costs for underground mining of thawed buried placers, the advantages for gold mining by the hydraulic borehole mining method are increasing. Based on mentioned above, the study of the application of the hydraulic borehole mining method in the conditions of Siberia and the Far East is a timely scientific task. Key words: Southern Yakutia, hydraulic borehole mining, alluvial gold, gold-bearing area, thickness of a seam, ore occurrences, concentration.
\end{abstract}

\section{Introduction.}

In the system of geotechnologies, hydraulic borehole mining is one of the main. With this method a production is carried out through wells at the same time with the help of energy of water and air, by means of which destruction of rocks, delivery of destroyed rocks to the well and lifting them to the surface $[1,2,3]$ are carried out.

\footnotetext{
*Corresponding author: viktor-rochev74@,mail.ru
} 
The most obvious objects for the application of hydraulic borehole mining are alluvial gold deposits. Here the sands are represented by easily disintegrated, disconnected or loosely connected rocks. A feature of the northern regions of the country is the presence of permafrost on placers, where there is a predominantly stable roof of the productive formation, which allows the extraction of large amounts of sands from the well without collapse.

Due to the depletion of surface reserves, large technical difficulties, significant capital investments and operational costs for the development of placer deposits in Siberia and the Far East, the prospect of gold mining by the hydraulic borehole mining method in rich deep-buried placers is increasing. [6]

Based on above mentioned, the study of the hydraulic borehole mining method application in conditions of permafrost is a timely scientific task.

In the field of hydraulic borehole mining studying, a great contribution was made by the following researchers: Arens [1-4], D.N. Shpak [13], P.M. Tupitsin [9], B.S. Fedorov [10], and many others. In addition, the method of mining through wells can be successfully used in the development of coal [12] and ore deposits [1,2,3,4,7,11], titanium-magnetite sands [5,6], as well as in the construction of underground reservoirs (for storage of oil, etc.) [8] and refrigerators [8].

To apply the hydraulic borehole mining method in conditions of permafrost, we were asked to conduct laboratory experimental studies to further use the results obtained at the alluvial gold deposit Middle Larba.

\section{Field characteristics.}

The Middle Larba field is located in the Tyndinskii district of the Amurskaia oblast, $62 \mathrm{~km}$ north-west of the district center of Tynda. The Baikal-Amur Mainline is $35 \mathrm{~km}$ to the south, the AYAM highway and the Tynda-Neryungri railway are $30-43 \mathrm{~km}$ to the east. The area of the object covers the valley of the upper course of the Middle Larba River from the mouth of the Arbat stream to the mouth of the Khorojchikan stream and is $53.86 \mathrm{~km}^{2}$.

Geographically, the relief of the area is medium-mountainous intensely dissected. The soils are represented by sandy-argillaceous rocks with inclusions of gravel. Alluvial gold laying depth is $5 \mathrm{~m}$. The temperature of frozen soils is $-3^{0} \mathrm{C}$.

Alluvial gold of the Middle Larba laying is located within the floodplain. The thickness of the loose sediments ranges from 2.0 to $6.7 \mathrm{~m}$, an average of $4.4 \mathrm{~m}$. The sediments of the Middle Larba are in a long permafrost state. Water bearing tabetisols are observed near the bed only.

The gold-bearing layer is confined to the lower horizons of the pebbles and the weathering crust of the bedrock. The thickness of the layer fluctuates from 0.4 to $2.8 \mathrm{~m}$, an average is 1.0 $\mathrm{m}$. Sands have high washability.

The placer bedrock consists of biotite granites, and less often gneisses broken up to the state of crushed stone and gravel, mostly to large blocks.

\section{Experiment technique.}

Based on the above data for the application of the hydraulic borehole mining method in laboratory conditions, we carried out experimental studies on the rocks brought from the given field with experimental unit presented on Fig. 1.

The simulated formation consisted from fine-grained sand, clay and gravel. Magnetite was used as a mineral. The roof and the soil of the reservoir corresponded to the maximum original conditions.

A sandy-argillaceous gravel mixture with a moisture content of up to $20 \%$ was placed in an experimental unit. Then, the mixture was frozen with the help of columns placed to a certain 
depth, into which the coolant (chladone-22) is pumped under pressure from the freon freezing station. Freezing of the rock was carried out to a temperature of $-35^{\circ} \mathrm{C}$ and then melted to $-3^{0} \mathrm{C}$.

A pulp-lifting tube (6) was built into the casing on the cotter pins (5) and then a supply pipe (7) with a smaller diameter was placed inside. At the top of the supply pipe were two nozzles: one was supplied with an water solution, and another with a certain pressure air. In the lower part there was a hydromonitor for washing of frozen rock. The supply pipe was adjusted in depth and rotated by $360^{\circ}$. The experiments were carried out with the diameter of the hydromonitor nozzles of 4,5;5,0;5,5 and $6 \mathrm{~mm}(8)$, water pressure from 0,03 to $0,07 \mathrm{mPa}$. In addition, an airlift with a diameter of $14 \mathrm{~mm}$ was used to create a vortex flow and a rapid entrance of the pulp and its passage through the pulp pipe.

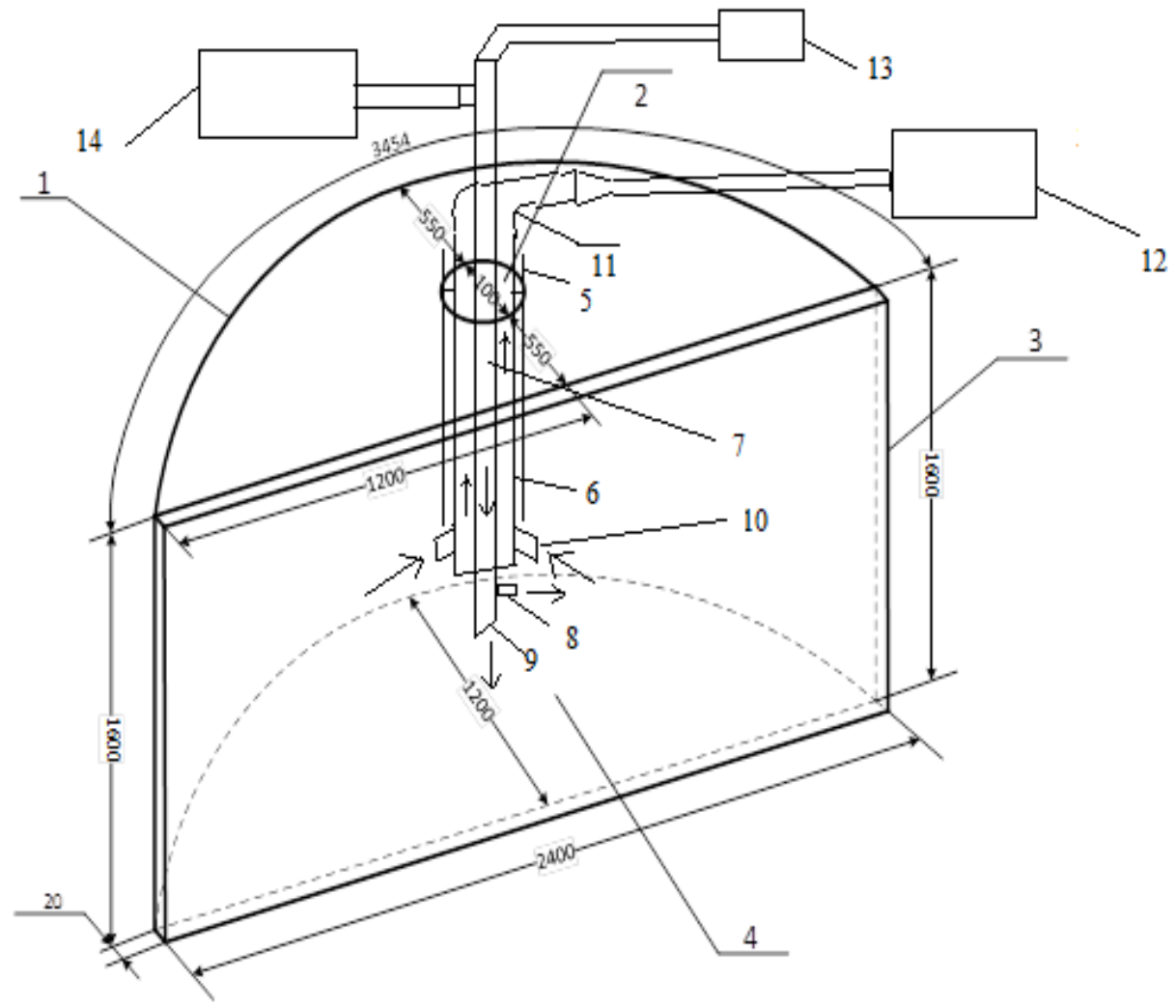

Fig. 1. Laboratory experimental unit for studying the processes of hydraulic borehole mining of send layout. 1 - removable lid, 2 - production well, 3 - plexiglass for observation, 4 - chamber, 5 - casing, 6 - pulp tube, 7 - water-air supply pipe, 8 - jetting nozzle, 9 - airlift, 10 - pulp input, 11 - head, 12-mud pump, 13 - centrifugal surface pump, 14 - compressor

In theory, increasing the diameter and pressure of water will increase the washing rate and increase the efficiency of the chamber [1]. However, the increase in efficiency is limited by the productivity of the pressure device. When minerals are mined from the top down, favorable conditions for the inflow of the slurry to the pressure device are created. A conical sump is formed around the hydroelevator inlet, and the jet acting on top will not interfere with the flow of the slurry.

A centrifugal surface pump (13) was used to supply water. Creation of vortex motion of the destroyed rock in the borehole and increase in water velocity was carried out with the help of a compressor (14). The mixture was removed to the surface by means of a mud pump (12). 


\section{Results and discussion.}

As a result of experimental studies it was found that the depth of destruction (Fig. 2) and the radius of destruction (Fig. 3) depends on the time. With the increase in time, the aforementioned indicators will increase.

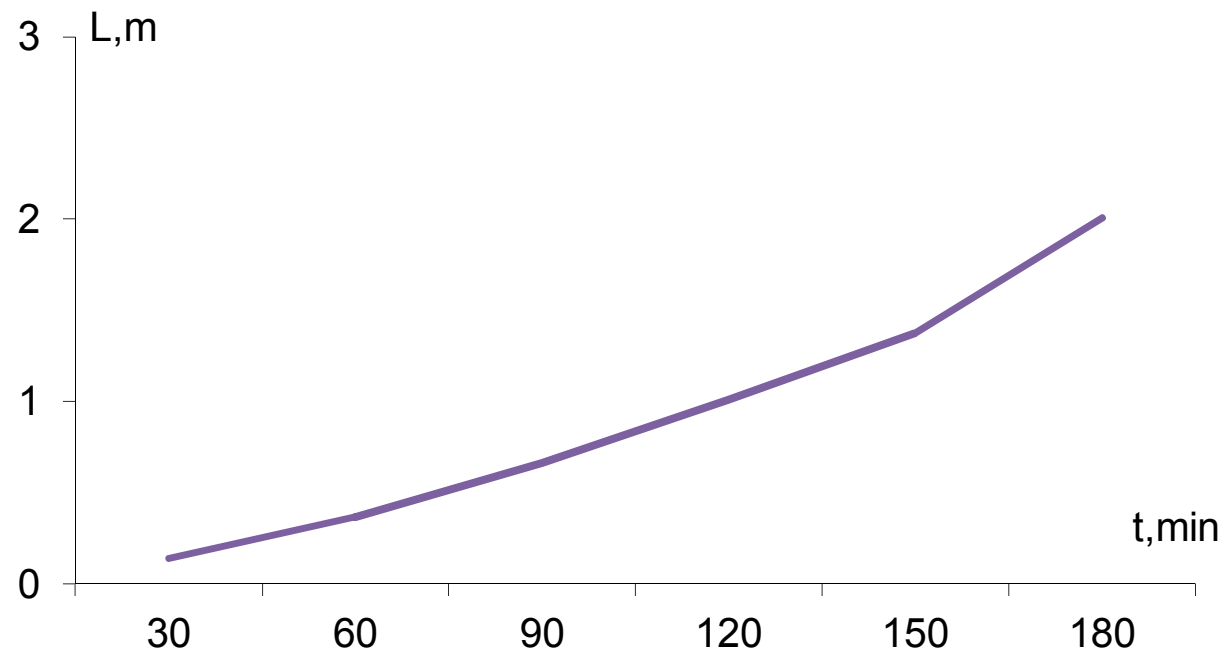

Fig. 2. Dependence of the destruction of frozen rocks depth on time.

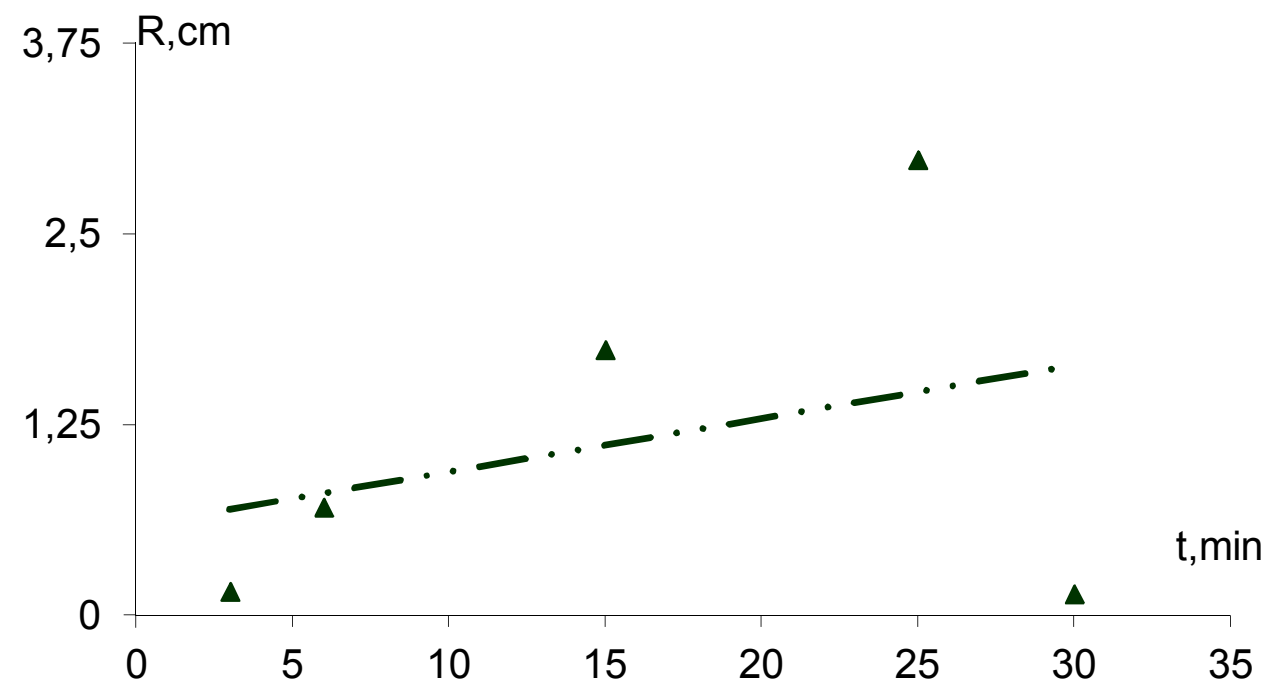

Fig. 3. Dependence of the radius of destruction of frozen rocks on time.

The effectiveness of hydraulic breaker on the diameter of the nozzle study has been carried out (Fig. 4). It can be seen that the radius of the destruction depends on the washing efficiency and the diameter of the nozzle of the hydromonitor. The radius of destruction increases with an increase in the diameter of the nozzle. 


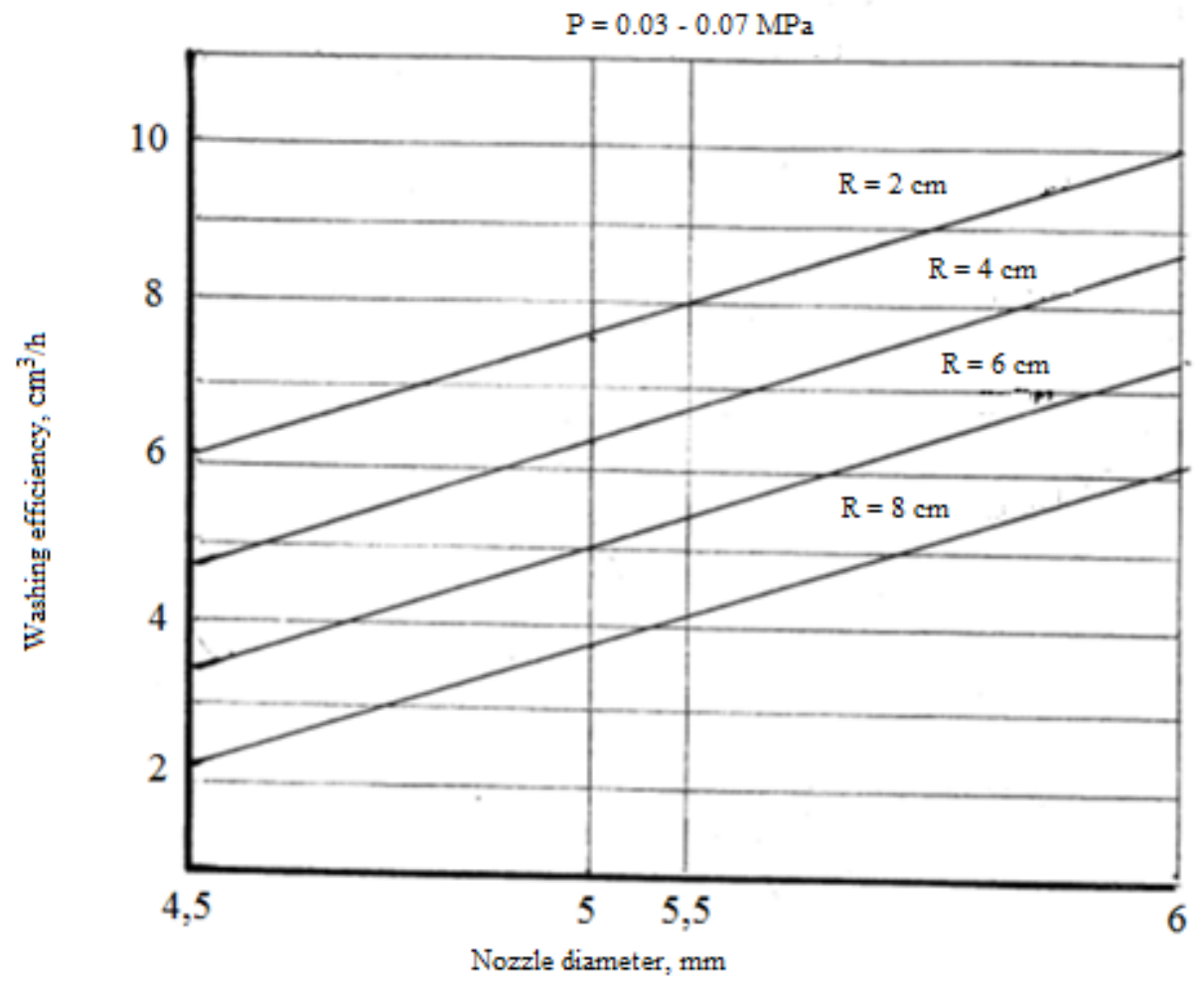

Fig. 4. Dependence of the productivity of a hydraulic breaker on the diameter of the nozzle.

The final result of the experimental studies was that a sandy-clay-gravel mixture and magnetite was elevated to the surface.

On the basis of experimental studies, we calculated all the parameters for using the hydraulic borehole mining method at the Middle Larba field.

Drilling of rocks to gold-bearing sands will be carried out by drilling rig URB 2A2 with casing pipes of $286 \mathrm{~mm}$ in diameter and with a coupling. Well-to-well distance is $40 \mathrm{~m}$.

It is proposed to develop the deposit with a mining projectile of the SGS-5 type with a washing by hydromonitor and a hydroelevator lifting of the gold-bearing slurry. Pulp is transported through the pipeline to the device PGSH-II-50 for further enrichment.

In addition, the diameter of the lifting pipe is $140 \mathrm{~mm}$, the diameter of the transported pipe is $113 \mathrm{~mm}$. For air supply, a compressor of the brand XAC47 with a capacity of 1.6 to $5 \mathrm{~m}^{3} /$ min will be used. As a feed pump, Grundfos CR series is proposed, with a capacity of up to 180 $\mathrm{m}^{3} / \mathrm{h}$. Water with a temperature of $+4^{0} \mathrm{C}$ will flow to the pump from a borehole drilled near it, and settle after being raised in 2 sump-settlers with a volume of up to $216 \mathrm{~m}^{3}$. The water pressure on the nozzles of the hydraulic monitor with a diameter of $20 \mathrm{~mm}$ is $3 \mathrm{mPa}$, the water pressure at the face is $0.6 \mathrm{mPa}$

To raise the hydrevlic fluid, an additional suction pump 8 НДв will be used.

\section{Conclusions}

As it was revealed from the analysis of geological materials there are a lot of gold deposits suitable for development by hydraulic borehole mining method in Siberia, and most of them are unsuitable for development by traditional methods (open and underground), because of their inefficiency, and can be proceeded by hydraulic borehole mining only. 
The hydraulic borehole mining method still requires huge scientific, technical and experimental study to improve its reliability and expand the field of application.

In the permafrost zone, sufficiently thick layers of frozen soils are widely distributed, where hydraulic borehole mining is possible. Such a development method will result in minor disturbances in the environment, provide safe working conditions and will allow for the automation of the processes of washing and rising of soil to the surface, and also achieve high technical and economic performances.

\section{References}

1. V. J. Arens, B.V. Ismagilov, D.N. Shpak, Hydraulic borehole mining of solid minerals. 229 p. (1980)

2. V. Zh. Arena, O.M. Gridin, E.V. Kreinin, V.P. Neber, M.I. Fazlullin, A.S. Khrulev, G.Kh. Hceyan, Physical and chemical geotechnology. (2010).

3. V.Zh. Ahrens, N.I. Babichev, A.D. Bashkatov et al., Hydraulic borehole mining of minerals. (2011).

4. V. Zh. Arens, G. Kh. Khcheyan, A. A. Khrulev. The Markscheider Herald. 3, 13-17. (2010).

5. Yu.P. Bobkov, S.I. Kulyapina, V.I. Mesitsi et al., Problems of Mountain Thermophysics. The II all Soviet Union scientific-techn. Conf. On mining technical thermophysics. 131-132 (1981).

6. V.P. Drobadenko, N.G. Malukhin, A.L. Wilmis, Gold mining. 155. 17-19. (2011).

7. O. V. Zamyatin, V. M. Mankov, Journal of Mining. 4, 22-26. (2011).

8. G.P. Kuzmin, A.V. Yakovlev, Underground reservoirs in frozen soils. (1992).

9. P.M. Tupitsyn, Device for underground mining of minerals by hydraulic method. Author. cert. of USSR № 58591, (1936).

10. B.S. Fedorov, P.A. Konovalov, Building Materials. (1974).

11. Kh. A. Sergeevich, Technology of hydraulic borehole mining of gold from buried permafrost placers (2002).

12. S.M. Shorokhov, Development of placer deposits and design basics (1963).

13. D.N. Shpak, Scientific and Technical Review. 4, 37. (1982). 